\title{
Single- Versus Double-Balloon-Assisted Colonoscopy After Previous Incomplete Standard Colonoscopy
}

\author{
Jun Uk Lim $\cdot$ Jae Myung Cha
}

Received: 24 May 2012/ Accepted: 6 July 2012/Published online: 26 July 2012

(C) Springer Science+Business Media, LLC 2012

Colonoscopy is the principle screening tool used for the detection of colorectal cancer and removal of colorectal adenomatous polyps $[1,2]$. Recently, a large clinical study showed that colonoscopic removal of adenomatous polyps reduced mortality from colorectal cancer by $53 \%$ [3]. While complete colonic evaluation is essential for screening colonoscopy, the rate of incomplete colonoscopy using a conventional standard colonoscope has been reported to be 5-10\% [4-6]. A study conducted in Ontario found that $43,483(13.1 \%)$ of 331,608 screening colonoscopies failed to evaluate the entire colon [7]. In this population-based cohort study, the factors associated with incomplete colonoscopy were increased patient age, female sex, a history of prior abdominal or pelvic surgery, and having the procedure done in a private office. Other predictors of incomplete colonoscopy include decreased functional status of the patient [8] and anatomic factors such as colonic elongation, tortuosity, and severe diverticulosis [9].

Malignant and pre-malignant lesions may go undetected in patients that are not completely evaluated by screening colonoscopy. In a population-based cohort study, $4.3 \%$ of advanced colonic neoplasms were missed by incomplete colonoscopy [10]. Since 33-50\% of advanced neoplasms are found only in the proximal colon [11-13], additional efforts should be made to adequately visualize the remaining colon after an incomplete colonoscopy. An alternative diagnostic modality such as computed tomographic colonography has been utilized in these cases, however, its

\footnotetext{
J. U. Lim · J. M. Cha (ه)

Department of Internal Medicine, Kyung Hee University Hospital at Gangdong, Kyung Hee University School of Medicine, 149 Sangil-dong, Gangdong-gu, Seoul 134-727, Korea

e-mail:drcha@khu.ac.kr
}

usefulness is limited by low sensitivity for small polyps, radiation exposure, and the inability to perform histologic biopsy and therapeutic procedures including polypectomy $[14,15]$. As a result, endoscopic approaches are still favored after incomplete standard colonoscopy. Additional endoscopic techniques using gastroscope, variable stiffness colonoscope, pediatric or cap-pitted colonoscope have been tried, but failed to achieve an adequate cecal intubation rate. More recently, a balloon-assisted technique, which was originally introduced to investigate the small bowel, has been applied in patients with previous failed or incomplete colonoscopy. For a balloon-assisted colonoscopy, two types of balloon enteroscopes are available; the double-balloon enteroscope developed by Yamamoto et al. [16], and the single-balloon enteroscope developed by Tsujikawa et al. [17]. The reported success rates of single- (SBC) or doubleballoon-assisted colonoscopy (DBC) in patients with previous incomplete conventional colonoscopy range from 88 to $100 \%$ [18-23].

In the current issue of Digestive Diseases and Sciences, Dzeletovic et al. [24] compared the performance outcomes of SBC and DBC in patients with previous incomplete conventional colonoscopy. In this study, the authors retrospectively reviewed 26 cases of SBC and 27 cases of DBC in patients whom underwent failed conventional colonoscopy. The current study showed that cecal intubation was successful in $96 \%$ of patients using either SBC or DBC (100\% with SBC vs. $93 \%$ with DBC, $p=0.049)$. The median cecal intubation time and total procedure time using SBC and DBC were $17 \mathrm{~min}$ vs. $20 \mathrm{~min}(p=0.37)$ and $43.5 \mathrm{~min}$ vs. $46.0 \min (p=0.32)$, respectively. While SBC required less time than DBC, the difference was not statistically significant. Balloon-assisted colonoscopy revealed additional colonic polyps in $35 \%$ of patients in the SBC group and $30 \%$ of patients in the DBC group. Despite the 
non-randomized retrospective study design and relatively small number of the subjects in the current study, it is the only study on this topic to date with the largest number of patients reported. Although patients were not prospectively randomized to SBC and DBC, they were assigned to a treatment group based on equipment availability in the endoscopy unit, and patient characteristics were comparable. Comparative analysis of SBC versus DBC following incomplete colonoscopy may be necessary both for the endoscopists who have to choose between SBC and DBC and for endoscopy centers which have to determine one platform for SBC or DBC. While SBC required less time than $\mathrm{DBC}$, the difference was not statistically significant in the current study [24]. However, a larger randomized controlled trial may be warranted to clarify any difference in performance outcomes between SBC and DBC after an incomplete colonoscopy.

In the literature, balloon-assisted colonoscopy has been increasingly recognized as an effective screening technique for patients in whom conventional colonoscopy has failed. The performance outcomes of the current study are comparable to those reported in previous studies. Retrospective and prospective studies using DBC [18-20] reported an 88-100 \% success rate for cecal intubation and 12-27 min of cecal intubation time. Several prospective studies using SBC [21-23] reported a 93-100\% success rate for cecal intubation and 30-50 min of total procedural time. Gay et al. [25] conducted a pilot study that reported cecal intubation rates of 82.5 and $80 \%$ and mean cecal intubation time of 12 and 18 min for DBC and SBC, respectively. In that study, however, SBC was performed in only five patients (four patients with long tortuous loops and one patient with an inflamed fixed colon) and performance outcomes of DBC and SBC are not directly compared. Therefore, meta-analysis regarding performance outcomes of DBC and SBC, which were performed separately for the failed conventional colonoscopy, may be helpful to support findings of the current study by Dzeletovic et al.

Incomplete conventional colonoscopy is not rare in our daily clinical practice, however, balloon-assisted colonoscopy is not an easy setting to perform routinely. Therefore, repeat standard colonoscopy with a gastroscope, pediatric colonoscope, or cap-pitted colonoscope and an adherence to strict basic technique with early reduction of loops and use of abdominal pressure should be tried first. However, when additional endoscopic techniques also fail to achieve cecal intubation, a switch to balloon-assisted colonoscopy should not be delayed. In other words, when the conventional and additional endoscopic techniques fail to achieve cecal intubation and there is a necessity for tissue sampling and polypectomy, the only remaining choice is balloon-assisted colonoscopy. The critical component of balloon-assisted colonoscopy may be flexibility of the enteroscope while navigating a narrowed colon lumen with the balloon of the enteroscope facilitating loop reduction and the overtube preventing loop formation. Therefore, the use of balloonassisted colonoscopy is more likely to ensure success when conventional colonoscopy failed due to looping and patient's intolerance. Although some patients with diverticulosis and colon angulation may be rescued with a pediatric colonoscope or gastroscope, a pediatric colonoscope or gastroscope may not facilitate loop reduction.

In summary, both single- and double-balloon-assisted colonoscopy should be recognized as effective techniques for patients who have failed complete conventional colonoscopy. SBC and DBC offer comparable high cecal intubation rates and high polyp detection rates, as well therapeutic options including polypectomy and histologic biopsy. Balloon-assisted colonoscopy would be selected as an endoscopic approach to perform histologic biopsy and therapeutic procedures for patients in whom conventional and additional endoscopic techniques have failed.

\section{Conflict of interest None}

\section{References}

1. Quintero E, Castells A, Bujanda L, et al. Colonoscopy versus fecal immunochemical testing in colorectal-cancer screening. $N$ Engl J Med. 2012;366:697-706.

2. Pox CP, Altenhofen L, Brenner H, Theilmeier A, Stillfried DV, Schmiegel W. Efficacy of a nationwide screening colonoscopy program for colorectal cancer. Gastroenterology. 2012;142:1460-1467.

3. Zauber AG, Winawer SJ, O'Brien MJ, et al. Colonoscopic polypectomy and long-term prevention of colorectal-cancer deaths. N Engl J Med. 2012;366:687-696.

4. Marshall JB, Barthel JS. The frequency of total colonoscopy and terminal ileal intubation in the 1990 s. Gastrointest Endosc. 1993;39:518-520.

5. Waye JD, Bashkoff E. Total colonoscopy: is it always possible? Gastrointest Endosc. 1991;37:152-154.

6. Church JM. Complete colonoscopy: how often? And if not, why not? Am J Gastroenterol. 1994;89:556-560.

7. Shah HA, Paszat LF, Saskin R, Stukel TA, Rabeneck L. Factors associated with incomplete colonoscopy: a population-based study. Gastroenterology. 2007;132:2297-2303.

8. Schmilovitz-Weiss H, Weiss A, Boaz M, Levin I, Chervinski A, Shemesh E. Predictors of failed colonoscopy in nonagenarians: a single-center experience. J Clin Gastroenterol. 2007;41:388-393.

9. Hanson ME, Pickhardt PJ, Kim DH, Pfau PR. Anatomic factors predictive of incomplete colonoscopy based on findings at CT colonography. AJR Am J Roentgenol. 2007;189:774-779.

10. Neerincx M, Terhaar sive Droste JS, Mulder CJ, et al. Colonic work-up after incomplete colonoscopy: significant new findings during follow-up. Endoscopy. 2010;42:730-735.

11. Imperiale TF, Wagner DR, Lin CY, et al. Using risk for advanced proximal colonic neoplasia to tailor endoscopic screening for colorectal cancer. Ann Intern Med. 2003;139:959-965.

12. Terhaar Sive Droste JS, Craanen ME, van der Hulst RW, et al. Colonoscopic yield of colorectal neoplasia in daily clinical practice. World J Gastroenterol. 2009;15:1085-1092.

13. Lieberman DA, Weiss DG, Bond JH, et al. Use of colonoscopy to screen asymptomatic adults for colorectal cancer. Veterans 
Affairs Cooperative Study Group 380. N Engl J Med. 2000;343: $162-168$.

14. Johnson CD, Chen MH, Toledano AY, et al. Accuracy of CT colonography for detection of large adenomas and cancers. $N$ Engl J Med. 2008;359:1207-1217.

15. Mulhall BP, Veerappan GR, Jackson JL. Meta-analysis: computed tomographic colonography. Ann Intern Med. 2005;142: 635-650.

16. Yamamoto H, Sekine Y, Sato Y, et al. Total enteroscopy with a nonsurgical steerable double-balloon method. Gastrointest Endosc. 2001;53:216-220.

17. Tsujikawa T, Saitoh Y, Andoh A, et al. Novel single-balloon enteroscopy for diagnosis and treatment of the small intestine: preliminary experiences. Endoscopy. 2008;40:11-15.

18. Pasha SF, Harrison ME, Das A, Corrado CM, Arnell KN, Leighton JA. Utility of double-balloon colonoscopy for completion of colon examination after incomplete colonoscopy with conventional colonoscope. Gastrointest Endosc. 2007;65:848-853.

19. Hotta K, Katsuki S, Ohata K, et al. A multicenter, prospective trial of total colonoscopy using a short double-balloon endoscope in patients with previous incomplete colonoscopy. Gastrointest Endosc. 2012;75:813-818.
20. Moreels TG, Macken EJ, Roth B, Van Outryve MJ, Pelckmans PA. Cecal intubation rate with the double-balloon endoscope after incomplete conventional colonoscopy: a study in 45 patients. J Gastroenterol Hepatol. 2010;25:80-83.

21. Keswani RN. Single-balloon colonoscopy versus repeat standard colonoscopy for previous incomplete colonoscopy: a randomized, controlled trial. Gastrointest Endosc. 2011;73:507-512.

22. Teshima CW, Aktas H, Haringsma J, Kuipers EJ, Mensink PB. Single-balloon-assisted colonoscopy in patients with previously failed colonoscopy. Gastrointest Endosc. 2010;71:1319-1323.

23. May A, Nachbar L, Ell C. Push-and-pull enteroscopy using a single-balloon technique for difficult colonoscopy. Endoscopy. 2006;38:395-398.

24. Dzeletovic I, Harrison ME, Pasha S, et al. Comparison of singleversus double-balloon-assisted colonoscopy for colon examination after previous incomplete standard colonoscopy. Dig Dis Sci. 2012. (Epub ahead of print). doi:10.1007/s10620-012-2227-z.

25. Gay G, Delvaux M. Double-balloon colonoscopy after failed conventional colonoscopy: a pilot series with a new instrument. Endoscopy. 2007;39:788-792. 